\title{
OJS

\section{EDUCAR PARA PRESERVAR: EXTENSÃO UNIVERSITÁRIA EM EDUCAÇÃO AMBIENTAL E SAÚdE PLANETÁRIA NA EDUCAÇÃO BÁSICA}

\author{
Cláudio José dos Santos Júnior ${ }^{1}$, Jackson Pinto Silva ${ }^{2}$
}

\begin{abstract}
${ }^{1}$ Discente de mestrado no Programa de Pós-graduação em Ensino na Saúde e Tecnologia da Universidade Estadual de Ciências da Saúde de Alagoas (UNCISAL).E-mail: claudiosantos_al@hotmail.com - ORCID iD: http://orcid.org/00000002-2853-1968;

${ }^{2}$ Mestre em Análise de Sistemas Ambientais. Geógrafo. Instituto Federal de Alagoas (IFAL). E-mail: jacksonpinto@bol.com.br-ORCIDiD: http://orcid.org/0000-0002-9592-0840
\end{abstract}

Artigo recebido em 13/10/2019 e aceito em 20/04/2020

\begin{abstract}
RESUMO
Objetivo: Relatar a experiência do Projeto de Extensão "Educar para preservar: levando a Educação Ambiental para as comunidades de Maceió". Métodos: Trata-se de estudo descritivo do tipo Relato de Experiência desenvolvido a partir de vivências de uma ação de extensão vinculada ao Instituto Federal de Alagoas Campus Maceió (IFAL). Resultados: O Projeto de Extensão teve como proposta a realização de ações educativas e a abordagem de conceitos básicos de sustentabilidade e educação ambiental. Foram trabalhados temas como saneamento básico, reciclagem, coleta seletiva e tráfico e direitos dos animais. O projeto contemplou 40 estudantes entre o $7^{\circ}$ e o $9^{\circ}$ ano do ensino fundamental de uma instituição de ensino fundamental de Maceió-AL. Os conhecimentos foram trabalhados em sala de aula, de forma dinâmica e interativa, utilizando metodologias ativas de aprendizagem. Os alunos eram livres para expressar suas opiniões em sala de aula sobre os temas propostos e, a cada conclusão de um novo tema, eram estimulados a multiplicar o conhecimento adquirido e desafiados a compartilhar seus aprendizados com sua comunidade (alunos de outras turmas, familiares, amigos e vizinhos). Considerações finais: Com a implementação do projeto contribuiu-se para o desenvolvimento de uma consciência crítica e sustentável acerca do tema "meio ambiente" por parte do público-alvo. A experiência viabilizou a abordagem das disciplinas de geografia e ciências de forma integrada e associada com o cotidiano dos estudantes.

Palavras-chave: Educação Ambiental. Sustentabilidade. Comunidade. Extensão.
\end{abstract}

\section{EDUCATE TO PRESERVE: UNIVERSITY EXTENSION IN ENVIRONMENTAL EDUCATION AND PLANETARY HEALTH IN BASIC EDUCATION}




\begin{abstract}
Objective: To report the experience of the Extension Project "Educating to preserve: taking Environmental Education to the communities of Maceió". Methods: This is a descriptive study of the Experience Report type developed from experiences of an extension action linked to the Federal Institute of Alagoas Campus Maceió (IFAL). Results: The Extension Project proposed educational activities and the approach to basic concepts of sustainability and environmental education. Topics such as basic sanitation, recycling, selective collection and trafficking and animal rights were worked on. The project included 40 students between the 7th and 9th grade of elementary school at an elementary school in Maceió-AL. The knowledge was worked in the classroom, in a dynamic and interactive way, using active learning methodologies. The students were free to express their opinions in the classroom about the proposed themes and, at each conclusion of a new theme, they were encouraged to multiply the knowledge acquired and challenged to share their learning with their community (students from other classes, family, friends and neighbors). Final considerations: With the implementation of the project, the target audience contributed to the development of a critical and sustainable awareness about the "environment" theme. The experience made it possible to approach the disciplines of geography and science in an integrated way and associated with the students' daily lives.
\end{abstract}

Keywords: Environmental Education. Sustainability. Community. Extension.

\title{
EDUCAR PARA PRESERVAR: EXTENSIÓN UNIVERSITARIA EN EDUCACIÓN AMBIENTAL Y SALUD PLANETARIA EN EDUCACIÓN BÁSICA
}

\begin{abstract}
RESÚMEN
Objetivo: Dar a conocer la experiencia del Proyecto de Extensión "Educar para preservar: llevar la Educación Ambiental a las comunidades de Maceió". Métodos: Se trata de un estudio descriptivo del tipo Informe de Experiencia desarrollado a partir de experiencias de una acción de extensión vinculada al Instituto Federal de Alagoas Campus Maceió (IFAL). Resultados: El Proyecto de Extensión propuso actividades educativas y el abordaje de conceptos básicos de sustentabilidad y educación ambiental. Se discutieron temas como saneamiento básico, reciclaje, recolección selectiva y tráfico y derechos de los animales. El proyecto incluyó a 40 alumnos de $7^{\circ}$ a $9^{\circ}$ de primaria de una escuela primaria de Maceió-AL. El conocimiento se trabajó en el aula, de forma dinámica e interactiva, utilizando metodologías de aprendizaje activo. Los estudiantes tuvieron libertad para expresar sus opiniones en el aula sobre los temas propuestos y, a cada conclusión de un nuevo tema, se les animó a multiplicar los conocimientos adquiridos y se les desafió a compartir su aprendizaje con su comunidad (alumnos de otras clases, familia, amigos y vecinos). Consideraciones finales: Con la implementación del proyecto, el público objetivo contribuyó al desarrollo de una conciencia crítica y sostenible sobre el tema del "medio ambiente". La experiencia permitió abordar las disciplinas de la geografía y la ciencia de forma integrada y asociada a la vida cotidiana de los estudiantes.
\end{abstract}

Palabras clave: Enseñanza de la geografía. Cambios climáticos. TIC.

\section{INTRODUÇÃO}

Nas últimas duas décadas a sociedade tem presenciado um crescimento importante dos movimentos pela preservação do meio ambiente. Esse fenômeno ocorre por que a população mundial tem mostrado que está cada vez mais consciente de que o modelo atual de desenvolvimento econômico, tanto em países desenvolvidos, como naquele em vias de desenvolvimento, está intimamente associado à degradação do meio ambiente, com impactos diretos na qualidade de vida e na própria sobrevivência da espécie humana (MARCATTO, 2002). 
Graças ao aumento do interesse pelas questões ambientais e aos recentes avanços tecnológicos e científicos, conhece-se mais sobre os problemas ambientais do que conhecia-se no passado. Essa realidade, porém, não tem sido suficiente para deter o processo de degradação ambiental em curso (MARCATTO, 2002).

Assim, a Educação Ambiental, especialmente aquela desenvolvida em meios formais de ensino, tem um papel tão fundamental, pois deve auxilia no desenvolvimento de uma consciência ética sobre todas as formas de vida com as quais o ser humano se compartilha neste planeta, respeitando seus ciclos vitais e impondo limites à exploração dessas formas de vida pelos seres humanos (WWF/ECOPRESS, 2000).

A degradação ambiental, noticiada pelos meios de comunicação e percebida cada vez mais por parte da população, é um dos maiores problemas da atualidade. Relata-se uma crise ambiental não só em escala local, mas em escala global, onde a exploração inadequada dos recursos naturais demandada por hábitos predatórios de consumo está comprometendo a existência da espécie humana (JACOBI, 2003).

Trata-se de uma crise profunda e complexa, civilizatória, na qual a degradação do meio ambiente é consequência da degradação de valores éticos, culturais, políticos que afligem e permeiam as sociedades. Assim, romper com esses processos de degradação e estabelecer novas formas em busca da sustentabilidade e da manutenção das formas de vida é o grande desafio de homens e mulheres (BONOTTO; CARVALHO, 2016).

O desenvolvimento sustentável necessita ser compreendido e incorporado ao mundo que cada pessoa constrói, em seu domínio de condutas, com as demais pessoas com quem convive. Isso leva a uma necessidade de qualificação das pessoas. A Educação Ambiental surge, então, como um esforço pedagógico de articular conhecimentos, metodologias e práticas ditadas pelo paradigma da sustentabilidade.

Para tanto, vários autores apontam a importância de abordar a educação ambiental no universo escolar, com o intuito de abordar conhecimentos que visem à conscientização e reflexão dos alunos frente às questões ambientais, tão importantes para os dias atuais (MARCATTO, 2002; BONOTTO; CARVALHO, 2016; MENEZES et al., 2018).

Medeiros et al. (2011) destacam a importância de tratar a questão ambiental no meio escolar, ressaltando as preocupações de instituições de ensino em se fazer esse tipo de abordagem, incorporando essa temática nos currículos escolares como temas transversais, contribuindo para a formação de cidadãos conscientes e agentes dessa mudança. Assim, o presente trabalho tem como 
tema a Educação Ambiental no âmbito escolar, especialmente a Educação Ambiental como instrumento de conscientização e reflexão.

\section{EDUCAÇÃO AMBIENTAL NA ESCOLA}

Carvalho (2006) traz que a Educação Ambiental deve considerada para além dos movimentos ecológicos. O autor traz que a prática de conscientização deve fazer parte da rotina das pessoas que, por sua vez, devem ser capazes de utilizar de forma racional os recursos naturais, assim como compreende sobre seu esgotamento e limitações do ambiente.

Silva \& Souza (2017) destacam que a Educação Ambiental encontra na escola um espaço privilegiado para estabelecer relações de construção de informação qualificada, que possibilitem criar condições e dar alternativas aos discentes, bem como estimulem os alunos a adotarem noções e posturas cidadãs, cientes de suas responsabilidades e, principalmente, perceberem-se como integrantes do meio ambiente.

Educação Ambiental, nessa perspectiva, consiste em um processo que proporciona uma formação crítica, além de mudanças de atitudes, adoção de uma posição consciente e participativa e de valores que se relacionam com a conservação dos recursos naturais. Demoly \& Santos (2018) enfatizam que a educação ambiental se coloca, na escola, como possibilidade de trabalho, e consiste em tema capaz de fazer com que os sujeitos, alunos e professores, se conectem com problemas cruciais do nosso tempo.

A Educação Ambiental tem assumido o papel desafiador de garantir a construção e solidificação de uma sociedade equilibrada e sustentável, em que se promovam, na relação harmoniosa entre o planeta e seus recursos, valores éticos como cooperação, solidariedade, generosidade, tolerância, dignidade e respeito à diversidade (CARVALHO, 2006).

Deve-se trabalhar a Educação Ambiental com o intuito de conscientização, conhecimento, comportamento, competência, capacidade de avaliação e participação. Esses objetivos têm como princípio o esclarecimento formador de uma atuação consciente dos sujeitos frente à problemática ambiental, buscar um novo comportamento que visa adquirir o sentido dos valores sociais, sensibilizando-os pelo interesse ao meio ambiente.

Brancalione (2016) destaca que a Educação Ambiental não deve ser limitada a um conteúdo ou disciplina específica, devendo ser temática integrante em diversas áreas do conhecimento e ser 
trabalhada independentemente da faixa-etária dos discentes e de acordo com o contexto, possibilitando a mediação e construção do conhecimento em conjunto entre alunos e mestres.

Com o ensino de Educação Ambiental, acredita-se, fielmente, que o aprendizado estimulado, levando-se em consideração a realidade local, pode favorecer uma visão mais prática dos problemas de degradação da natureza e a busca por soluções mais criativas e especificas, de maneira que permita as pessoas enxergarem sua realidade e atuação no meio (BORGES; JUNIOR, 2017).

A Educação Ambiental é um jogo de palavras que pode ser traduzido como: conteúdo e aprendizado, é motivo e motivação, é parâmetro e norma. Vai além dos conteúdos pedagógicos, interage com o ser humano de forma que a troca seja uma retroalimentação positiva para ambos. Educadores ambientais são pessoas que em seus olhos e em todo corpo possuem a paixão pelo que fazem. E, para que o respeito seja o primeiro sentimento motivador das ações, é preciso que a escola use suas regras para se fazer educação ambiental de uma forma mais humana (CARVALHO, 2006).

No Brasil, Educação Ambiental apresentou-se em duas faces, a primeira como um modismo desenfreado e através do oportunismo; a segunda, que predomina atualmente, como uma opção pedagógica crítica aos modelos vigentes (BRANVALIONE 2016).

No Fórum Global da Rio-92, as organizações não governamentais formularam o Tratado de Educação Ambiental para Sociedades Sustentáveis e Responsabilidade Global e estabeleceram alguns princípios, dos quais podem-se citar: i) a educação ambiental é um direito de todos; ii) somos todos aprendizes e educadores; iii) deve ter como base o pensamento crítico e inovador em qualquer tempo ou em seus modos formal, não formal e informal, promovendo a transformação e a construção da sociedade; iv) é individual e coletiva e tem o propósito de formar cidadãos com consciência local e planetária que respeitem a autodeterminação dos povos e a soberania das nações; v) a educação ambiental não é neutra, mas ideológica; vi) deve integrar conhecimentos, aptidões, valores, atitudes e ações, convertendo cada oportunidade em experiências educativas de sociedades sustentáveis.

A Educação Ambiental é uma das mais importantes exigências educacionais contemporâneas, pois busca ampliar a participação política do cidadão como promotor de um ambiente saudável à convivência humana. Essa prática deve ser inserida desde cedo na rotina das pessoas, viabilizando a construção de uma nova perspectiva sobre meio ambiente, sobre o uso dos recursos naturais e da sustentabilidade. Portanto,

Portanto, tendo como referência tais pressupostos e das possibilidades de construção do conhecimento do ambiente formal de ensino, desenvolvemos o Projeto de Extensão "Educar para preservar: levando a Educação Ambiental para as comunidades de Maceió” e, neste trabalho, 
relataremos a experiência de Educação Ambiental desenvolvida em uma instituição de ensino fundamental de Maceió-AL.

\section{MÉTODOS}

O presente trabalho configura-se como um estudo exploratório do tipo relato de experiência. Seu objetivo é descrever as vivências oportunizadas pelas práticas do Projeto de Extensão Universitária "Educar para preservar: levando a Educação Ambiental para as comunidades de Maceió", do Instituto Federal de Alagoas - Campus Maceió (IFAL), desenvolvido durante o ano de 2018 com estudantes do ensino fundamental de uma escola pública de ensino fundamental de Alagoas. As atividades foram desenvolvidas como parte complementar das disciplinas "ciências" e "geografia" e buscou integrar conhecimentos presentes da realidade dos próprios discentes.

Para a construção do presente trabalho foram empregadas as reflexões dos membros do Projeto acerca das ações por eles experimentadas e utilizados registros escritos e fotográficos extraídos do "diário de bordo" da ação de extensão.

No início do Projeto foi realizado um levantamento bibliográfico sobre as temáticas que envolvem a Educação ambiental, utilizando-se de revisão bibliográfica, além de consulta a artigos e livros que abordavam os conteúdos que foram tratados no decorrer do projeto, a fim de embasar os conteúdos estudados.

Em seguida, ocorreu o primeiro contato com a instituição de ensino Escola Estadual Dom Pedro II, por meio de visitas e envio de ofícios, tendo como resposta o aceite e a aplicação do projeto. Foram realizadas reuniões com a direção, coordenação e professores de Ciências e Geografia para a definição da pertinência temática e linha de abordagem. Após toda essa etapa de formalização do projeto, foi necessária a divulgação do projeto nas salas de aulas das escolas como forma de despertar o interesse de alunos na formação de uma turma interessada na temática. Foram desenvolvimentos materiais educativos para uso na explanação dos conteúdos.

As atividades foram ministradas por dois facilitadores (bolsistas) que forneceram informações básicas e estimularam a análise crítica e a busca por soluções criativas para os conflitos socioambientais mais comuns atualmente nos cenários local e global. Os encontros ocorreram semanalmente no contra turno. Foram formadas 2 (duas) turmas de 20 alunos, totalizando 40 discentes, em períodos distintos, sendo que a segunda turma teve início quando a primeira findou. A exposição dos conteúdos durante as atividades do projeto foi apoiada por recursos de áudio, vídeos, 
textos, dinâmicas e oficinas práticas. Os temas foram analisados em sala de aula pelas perspectivas sociais, ambientais e econômicas.

A capacitação proporcionou ao aluno uma formação integrada, com a sistematização de conteúdos importantes para que ele tivesse a capacidade de compreender o significado das mudanças climáticas atuais em função dos impactos ambientais nas suas diferentes escalas de ocorrência, assim como o seu papel como educador nas questões ambientais de sua região, numa visão holística e sustentável da relação ser humano e natureza.

A parte teórico-prática do projeto contou com a realização de oito (oito) oficinas educativas desenvolvidas com auxílio de áudio, vídeos, slides, jogos didáticos e textos. Os alunos também foram desafiados a realizar pesquisas fora da sala de aula e a confecção de redações e paródias sobre assuntos aprendidos. Para distanciar o discente da abordagem tradicional da sala de aula e visando evitar o desinteresse em relação ao projeto, não foram atribuídas notas ou pontuação aos trabalhos e atividades desenvolvidas, tendo sido priorizadas discussões realizadas durante as próprias oficinas. Por se tratar de estudo onde foram expostas reflexões produzidas pelos próprios autores, não houve a necessidade de submissão a Comitê de Ética nem de formalização de Termo de Consentimento Livre Esclarecido.

\section{RESULTADOS}

O ambiente escolhido para realização dessa atividade foi o meio escolar. Optou-se pelo cenário descrito por entendermos que esse espaço tem o papel de formar pessoas com capacidade criativa e crítica para enfrentar a realidade e que a educação tem o poder de dar condições para que os alunos, e futuros cidadãos-profissionais, construam seus conhecimentos, criem, questionem e exerçam suas próprias potencialidades. O conteúdo do projeto foi separado em módulos-temáticos, conforme discriminados a seguir:

Tabela 1. Conteúdo das oficinas

\begin{tabular}{|c|l|}
\hline Etapa & \multicolumn{1}{c|}{ Conteúdos } \\
\hline & O que é Educação Ambiental? \\
& Legislação brasileira sobre educação ambiental \\
Unidade 1 & Política Nacional de Educação Ambiental \\
& Meio Ambiente \\
& Sustentabilidade \\
\hline
\end{tabular}




\begin{tabular}{|c|c|}
\hline & $\begin{array}{l}\text { Ações sustentáveis } \\
\text { Desenvolvimento sustentável } \\
\text { Sugestões para o desenvolvimento sustentável }\end{array}$ \\
\hline Unidade 2 & $\begin{array}{l}\text { A água } \\
\text { Importância da água para o ser humano } \\
\text { A poluição da água } \\
\text { Saneamento básico } \\
\text { O tratamento da água } \\
\text { Economia de água } \\
\text { Dicas para a economia de água } \\
\text { A poluição do ar } \\
\text { Ações para reduzir esses efeitos }\end{array}$ \\
\hline Unidade 3 & $\begin{array}{l}\text { Energias renováveis e não-renováveis } \\
\text { Economia de Energia Elétrica } \\
\text { Consumo sustentável } \\
\text { Desenvolvimento Sustentável } \\
\text { Consumo e desenvolvimento sustentável } \\
\text { Coleta seletiva } \\
\text { Reciclagem } \\
\text { Reciclagem e coleta seletiva } \\
\text { Os materiais recicláveis }\end{array}$ \\
\hline Unidade 4 & $\begin{array}{l}\text { Cenário Ambiental } \\
\text { A Amazônia } \\
\text { Tráfico de animais } \\
\text { Direitos dos animais } \\
\text { Alimentos Orgânicos } \\
\text { Agrotóxicos } \\
\text { Alimentos transgênicos } \\
\text { Desperdício de alimentos }\end{array}$ \\
\hline
\end{tabular}

Fonte: elaborado pelos autores, 2019.

As ações foram desenvolvidas a partir da exposição-dialogada dos temas e tiveram como apoio a utilização de materiais impressos, apostilas e recursos audiovisuais. Foram aplicados, ainda, dois brinquedos pedagógicos desenvolvidos pela equipe do projeto. Os jogos versavam sobre as temáticas "fontes de energia" e "dinâmica climática". 
Figura 1, 2 e 3. Dominó Geográfico "Fontes de Energia" e Baralho "Dinâmica Climática"
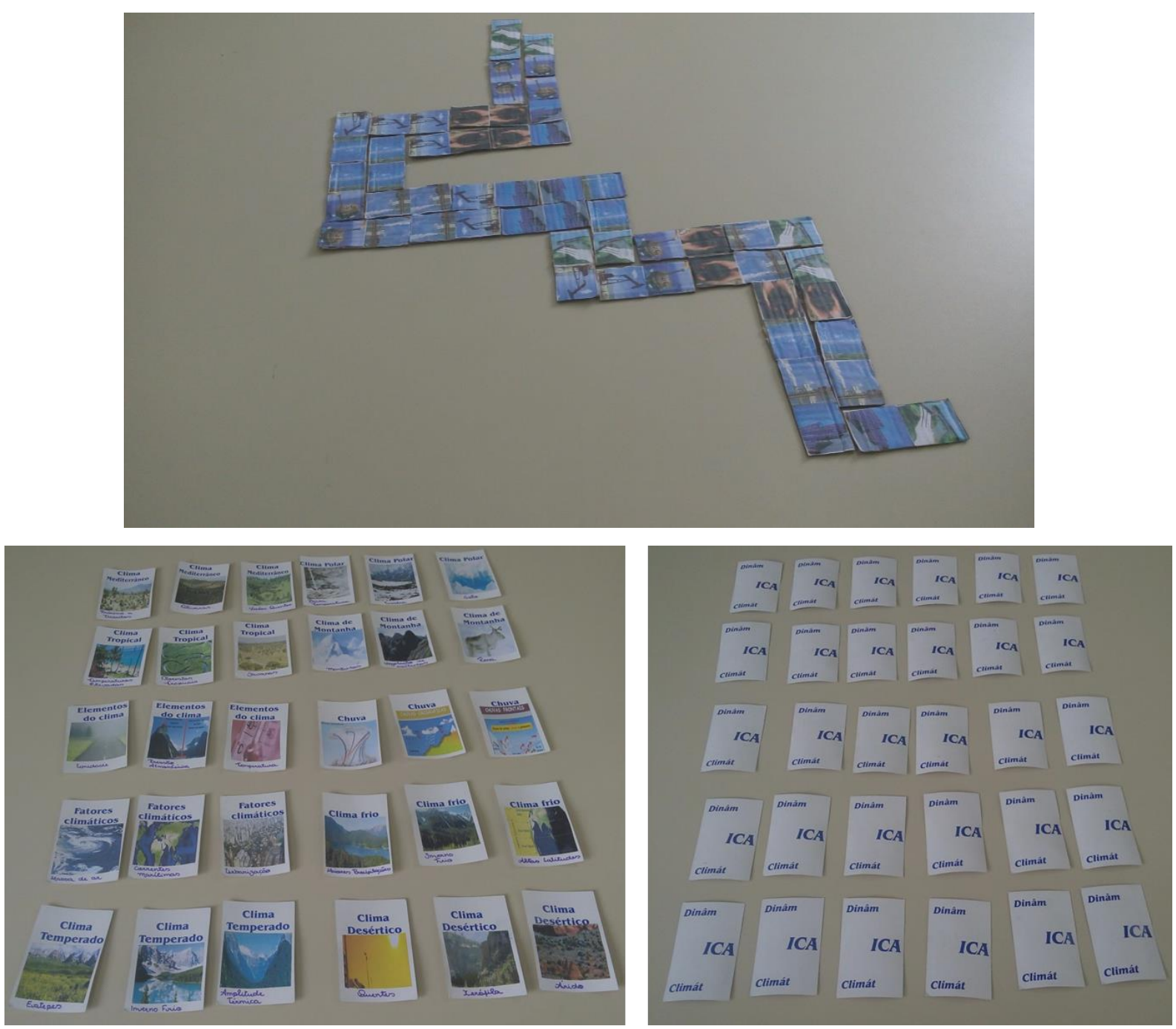

Fonte: acervo dos autores, 2019.

Nas oficinas, eram realizadas atividades escritas, debates e dinâmicas em grupo, buscando despertar o constante interesse dos participantes sobre os assuntos abordados. 
Figura 3. Exposição de cartazes produzidos pelos participantes do Projeto com a temática Preservação Ambiental.

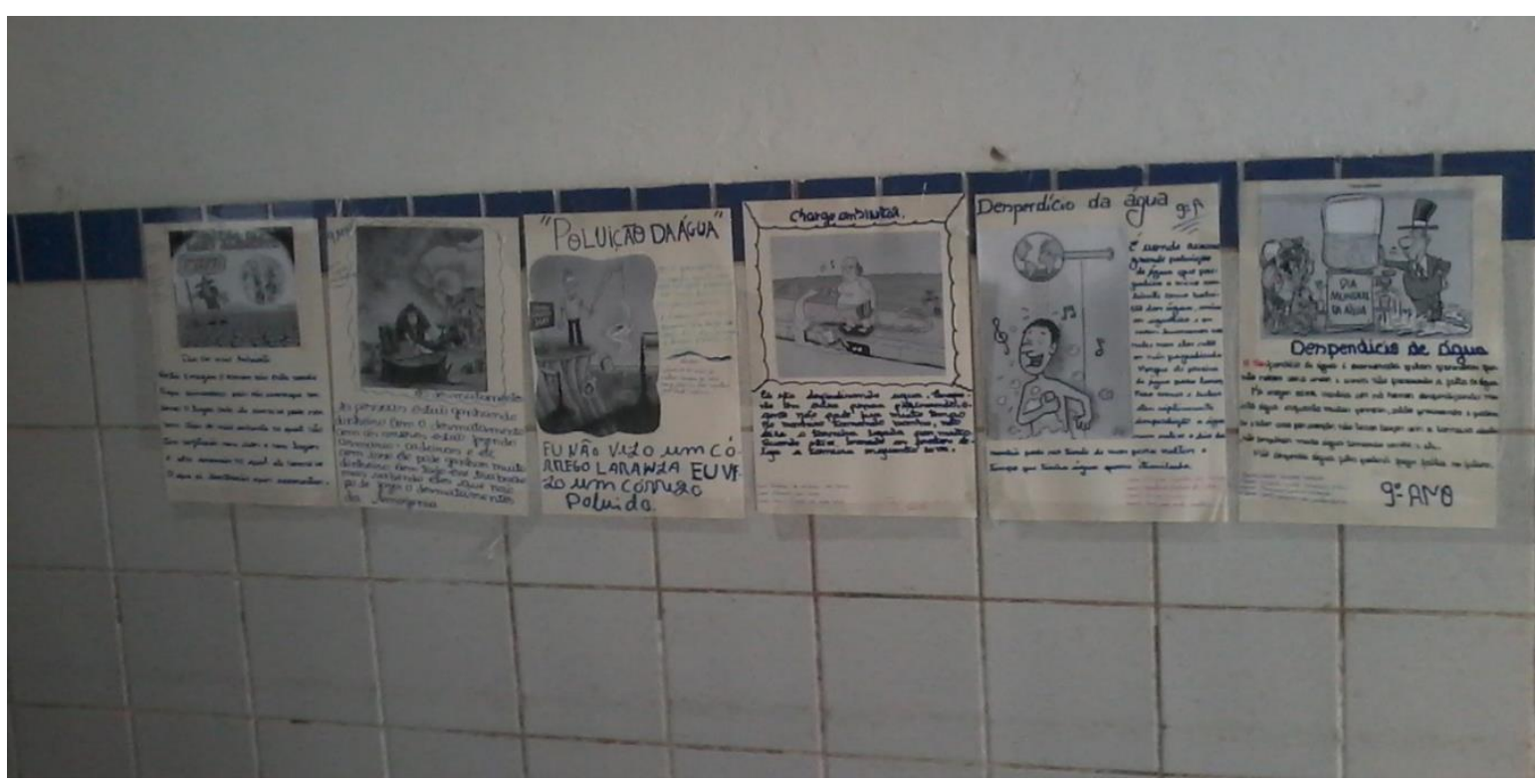

Fonte: acervo dos autores, 2019.

Durante a realização das atividades estimulou-se o protagonismo discente, a participação e a geração questionamentos sobre os temas explanados. Os discentes compartilhavam seus pontos de vista e até mesmo soluções para as problemáticas ambientais abordadas.

Figura 4. Registro fotográfico de uma oficina pedagógica.

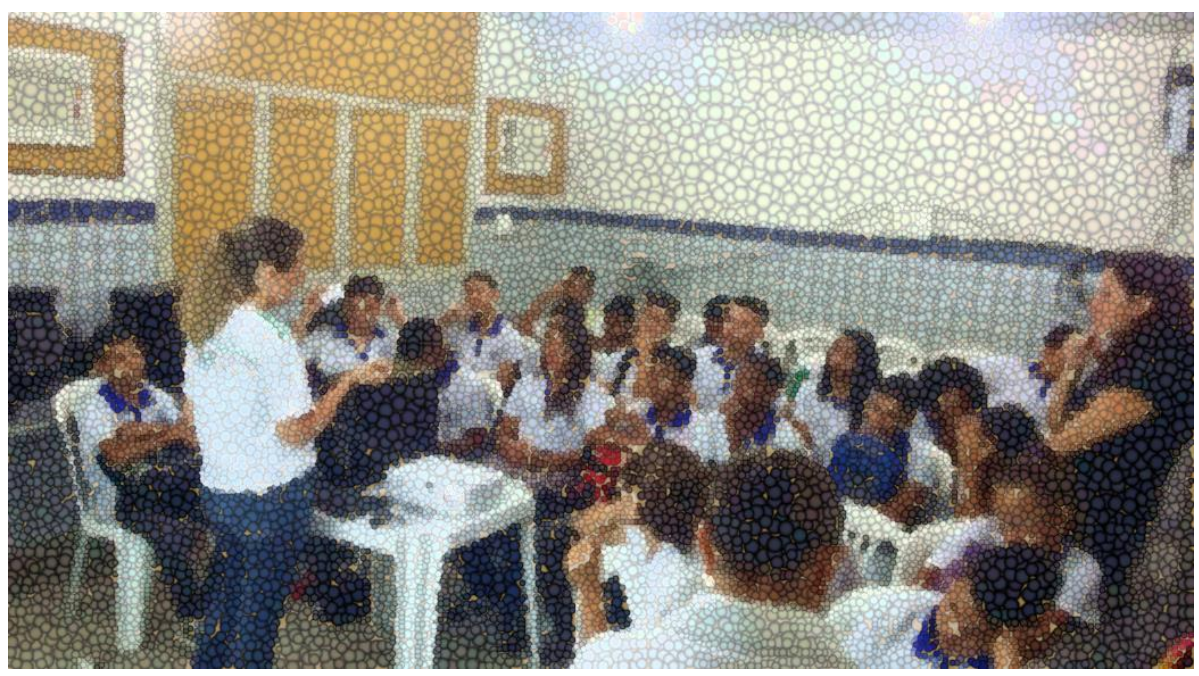

Fonte: acervo dos autores, 2019. 
Os discentes eram estimulados a trazer exemplos práticos das realidades apresentadas durante as oficinas didático-pedagógicas. A cada encontro os alunos lapidavam o que o grupo chamou de "consciência sustentável". Os conhecimentos foram adquiridos tanto na sala de aula quanto fora dela.

Figura 5. Registro fotográfico de uma oficina pedagógica.

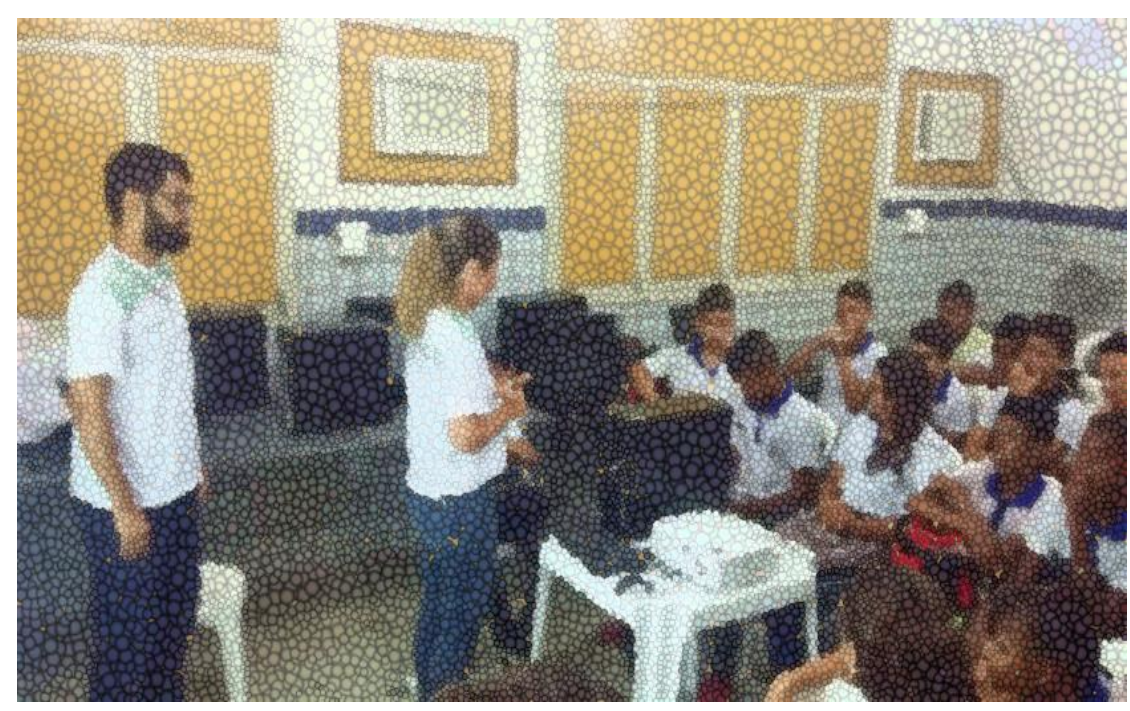

Fonte: acervo dos autores, 2019.

Buscou-se correlacionar os assuntos-temas das oficinas com realidade dos discentes e de seus familiares, de modo que, ao final de cada nova aula, os alunos eram desafiados a compartilhar seus novos conhecimentos e atuarem como agentes transmissores dos conteúdos abordados nas atividades, atuando como multiplicadores em suas residências, vizinhança e até mesmo na cidade, extrapolando o ambiente escolar.

Os instrutores e os alunos, ao final das oficinas, buscavam sintetizar aquilo que foi transmitido em sala por meio da elaboração de mapas mentais e diagramas-resumo, para uma melhor fixação das temáticas. Cada aluno era desafiado a resumir em uma frase e/ou em um conjunto de palavras-chave o que mais do tema abordado. Os discentes eram estimulados, também, a responder ao questionamento: "como eu poderia colocar em pratica na minha comunidade os conteúdos dessa oficina?". 
Revista Ensino de Geografia (Recife) V. 3, No. 2, 2020

DOI: https://doi.org/10.38187/regeo2020.v3n2id242973

Tabela 2. Síntese dos resultados alcançados

\begin{tabular}{|c|c|c|}
\hline DESCRIÇÃO & AÇÕES & PÚBLICO \\
\hline Escola Estadual Dom Pedro II & 8 oficinas educativas & $\begin{array}{c}21 \text { estudantes com } \\
\text { faixa etária entre 13 } \\
\text { e } 15 \text { anos }\end{array}$ \\
\hline Escola Estadual Dom Pedro II & 8 oficinas educativas & $\begin{array}{c}19 \text { estudantes com } \\
\text { faixa etária entre 12 } \\
\text { e 17 anos }\end{array}$ \\
\hline
\end{tabular}

Fonte: elaborado pelos autores, 2019.

Através da pergunta “O que você entende por educação ambiental?", a qual foi aplicada no término da capacitação, pode-se dimensionar o aprendizado dos alunos de forma individualizada, além de perceber os principais temas com os quais os participantes desenvolveram maior afinidade. Algumas das respostas estão apresentadas a seguir.

"É respeitar o meio ambiente, tendo a consciência sustentável sobre como devemos cuidar do meio ambiente para ter a maior duração dos recursos naturais para que nossos filhos e netos possam usufruir também. (Aluno 1)

"É ter uma visão ambiental, social e econômica sobre o modo inteligente de usar os recursos naturais, respeitando o meio ambiente e a sociedade. "(Aluno 2)

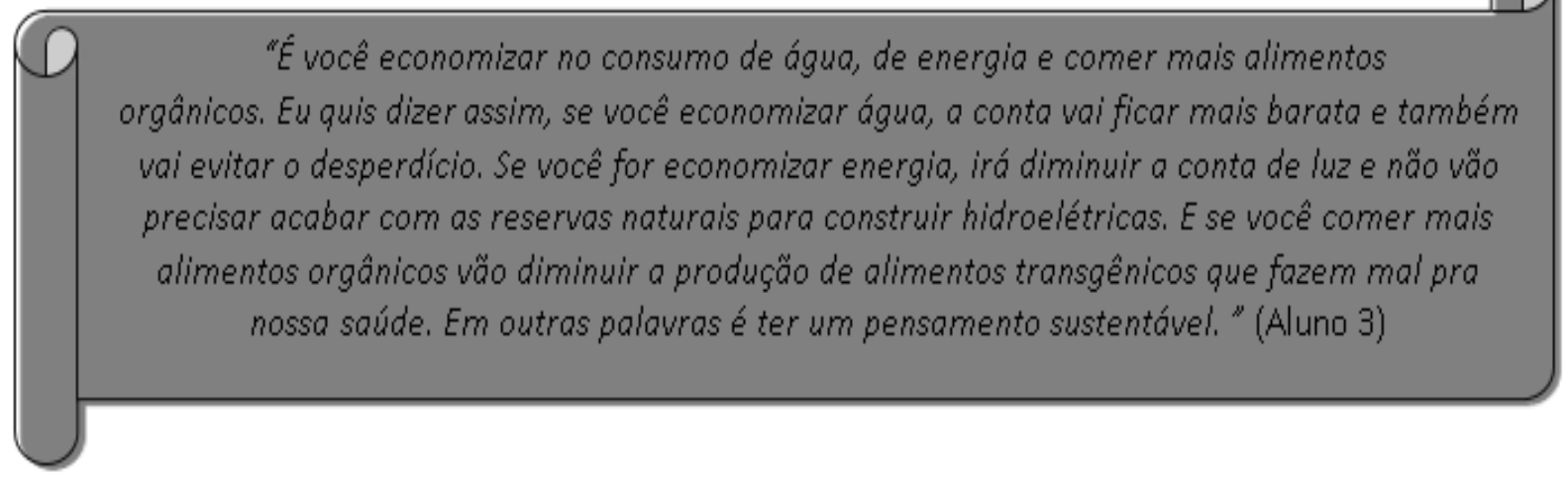

$\mathrm{Na}$ avaliação do Projeto pelos discentes 30 alunos (75\%) afirmaram estarem "muito satisfeitos" com a atividade; $8(20 \%)$ consideraram satisfatório o projeto, afirmando estarem 
"satisfeitos" com as atividades; e 2 (5\%) assumiram posicionamento "neutro". Nenhum participante assinalou os itens "insatisfeito" ou "muito insatisfeito" para categorizar a atividade.

Figura 6. Gráfico de avaliação da ação pelo público alvo ( $n^{\circ}$ de respondentes: 40)

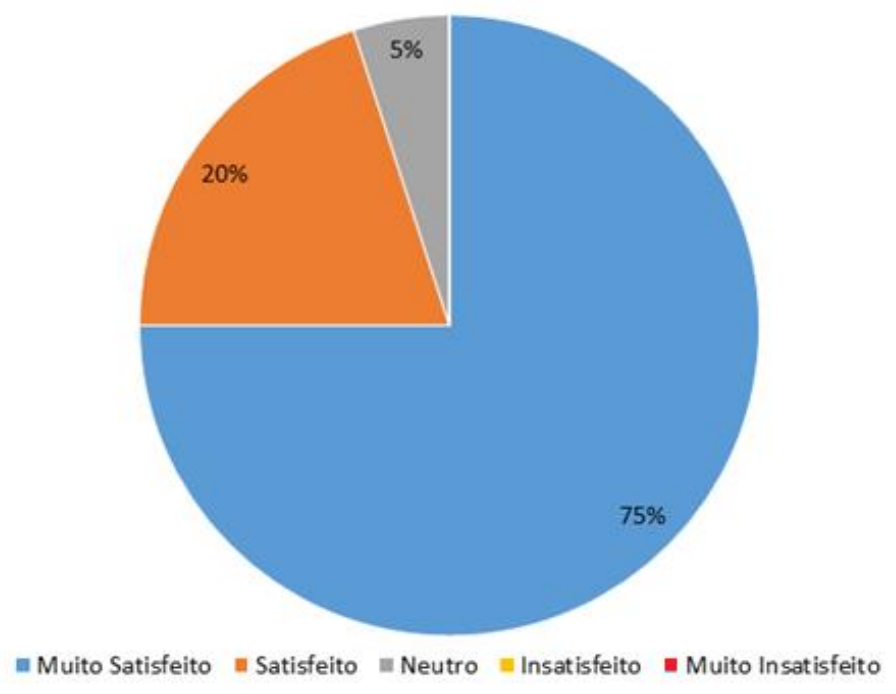

Fonte: dados da pesquisa, 2019.

Convém ressaltar, portanto, a consciência ambiental adquirida pelos participantes, que puderam compreender a importância de práticas sustentáveis para a preservação dos recursos ecológicos do planeta e ofeedback positivo em relação projeto. Assim, destaca-se que os participantes demonstraram interesse pelos assuntos abordados, reafirmando o interesse da comunidade estudantil acerca dos temas propostos quando da utilização de metodologias ativas de ensino - tal qual as que foram apresentadas.

\section{CONSIDERAÇÕES FINAIS}

O projeto cumpriu com sua finalidade de "educar para preservar", tendo levado o tema da Educação Ambiental para um grupo de jovens estudantes do ensino fundamental e despertado interesse dos mesmos para o estudo da temática e de modo a formar cidadãos conscientes de suas ações no que diz respeito à preservação do meio em que vivemos e buscar a conscientização sobre a importância da preservação dos recursos naturais.

Com a implementação das oficinas, contribuiu-se para o desenvolvimento de uma consciência crítica e sustentável acerca do tema "meio ambiente" por parte do público-alvo. A 
experiência viabilizou a abordagem das disciplinas de geografia e ciências de forma integrada e associada com o cotidiano dos estudantes.

Projetos curriculares e atividades de extensão nesse segmento precisam ser estimulados, com o fim de fazer com que o tema da Educação Ambiental passe a fazer parte da rotina dos alunos em vista de serem viabilizadas melhores condições de vida às atuais e futuras gerações.

\section{REFERÊNCIAS}

BONOTTO, D. M. B; CARVAlHO, M. B. S. S. Educação Ambiental e valores na escola: buscando espaços, investindo em novos tempos. São Paulo: Cultura Acadêmica, 2016.

BORGES, Aylana Laíssa Medeiros; JUNIOR, João Correia Saraiva. A Educação Ambiental no âmbito escolar: um estudo em uma escola municipal de Sítio Novo (RN). Revista Brasileira de Educação Ambiental, São Paulo, v. 11, n. 5, p. 115-122, 2016.

BRANCALIONE, L. Educação ambiental: refletindo sobre aspectos históricos, legais e sua importância no contexto social. Revista do IDEAU, v. 11, n. 23, 2016.

CARVALHO, I. C. M. Educação ambiental: a formação do sujeito ecológico. 2. ed. São Paulo: Cortez, 2006.

DEMOLY, K. R. A.; SANTOS, J. S. B.. Aprendizagem, educação ambiental e escola: modos de emagir na experiência de estudantes e professores. Ambient. soc.. 2018, vol.21, e00872. 2018. https://doi.org/10.1590/1809-4422asoc0087r2vu1811ao.

JACOBI, Pedro. Educação ambiental, cidadania e sustentabilidade. Cad. Pesqui. [online], n. 118, p. 189-206, 2003. https://doi.org/10.1590/S0100-15742003000100008.

MARCATTO, Celso Educação ambiental: conceitos e princípios. Belo Horizonte: FEAM, 2002. 64 p.

MEDEIROS, B. A. et al. A Importância da educação ambiental na escola nas séries iniciais. Revista Faculdade Montes Belos, v. 4, n.1, 2011.

MENEZES, J. B. F. de et al. Conceitos, práticas de educação ambiental e formação cidadã na escola. Ambiente e Educação: Revista de Educação Ambiental, Rio Grande, v. 23, n. 1, 2018.

PADUA, Suzana Machado. A Importância da EA na Proteção da Biodiversidade no Brasil. 2018. Disponível em: https://bit.ly/3eft1TF. Acesso em: 13 de abril 2020.

SILVA, M. A.; SOUZA, R. E. Ensino da educação ambiental no cotidiano do espaço escolar. Revista da EVASF, v. 7, n.13, p. 112-116, 2017. 
Revista Ensino de Geografia (Recife) V. 3, No. 2, 2020

DOI: https://doi.org/10.38187/regeo2020.v3n2id242973

Tratado de Educação Ambiental Para Sociedades Sustentáveis e Responsabilidade Global. 1992. Disponível em: <https://bit.ly/2K0C0dI>. Acesso em: 13 de abril 2020. 